Peer-Reviewed Article

ISSN: 2162-3104 Print/ ISSN: 2166-3750

Online Volume 7, Issue 3 (2017), pp. 764-785

(C) Journal of International Students

http://jistudents.org/

doi: 10.5281/zenodo.570033

\title{
Strategies to Address \\ English Language Writing Challenges Faced by International Graduate Students in the US
}

\author{
Swathi Ravichandran \\ Kent State University, USA \\ Mark Kretovics \\ Kent State University, USA \\ Kara Kirby \\ Global Ambassadors Language Academy, USA \\ Ankita Ghosh \\ Education for Innovation, Inc, USA
}

\begin{abstract}
Since 2000, there has been a $72 \%$ increase in the number of international students attending US institutions of higher education. The increase, specifically of international graduate students, has brought to light the writing challenges experienced by this population of students. This study explored specific writing challenges experienced by international graduate students and determined strategies to alleviate these challenges. Interviews were conducted with 15 international graduate students representing a variety of geographic backgrounds and disciplines. Responses revealed that writing challenges faced related to grammar and vocabulary, organization and flow of ideas, critical thinking, and plagiarism. Participants offered specific suggestions on how subject-matter faculty, friends, and peer mentors could assist in improving English-language writing skills. Implications for higher education institutions are discussed.
\end{abstract}

Keywords: ESL, international student, writing challenges, English, graduate students

A number of English-language writing challenges faced by international students including issues with grammar, vocabulary, plagiarism, linguistic fluency and accuracy (Storch, 2009) have been widely reported in the literature. Past studies have focused specifically on East Asian and Middle- 
Eastern students, a growing population in US educational institutions for whom such barriers are more profound (Longerbeam, DeStefano, \& Lixin, 2013; Poyrazli, Arbona, Bullington, \& Pisecco, 2001). As a result of these challenges, international students experience isolation and lack of belonging and unfair perceptions (Hanassab, 2006) or underestimation of their academic ability (Choi, 2006).

Language proficiency contributes heavily to the success of specifically, international graduate students (Andrade, 2006). This is because graduate programs typically have a significant capstone writing requirement such as a thesis or a project with more intensive writing expectations. Therefore, the impact of any shortcomings in Englishlanguage writing skills is exacerbated among international graduate students as the writing expectations are much higher compared to undergraduate coursework.

Despite there being a positive correlation between strong writing skills and academic achievement (Andrade, 2006), the literature with respect to support needed for academic writing for students whose first language is not English is sparse. As Zhou, Frey, and Bang (2011) recommended, schools should survey international graduate students and hear their voices in order to understand their academic needs. Andrade (2006) added that success factors of international students should be determined through interviews and focus groups and not just GPA and retention rates. Hence, the objectives of this qualitative study are two-fold: (a) To gain an understanding of the nature of English-language writing challenges faced by international graduate students in the US whose first language is not English; and (b) to determine strategies that could be utilized to improve English-language writing skills for international graduate students whose first language is not English. Findings from this study provide for a more thorough understanding of writing challenges from the perspective of international graduate students and also provide subject-matter instructors (as opposed to only English-language instructors) with a list of strategies that can be implemented in the classroom to address writing challenges.

\section{LITERATURE REVIEW}

\section{Enrollment of International Students in US Colleges and Universities}

According to the Institute of International Education, the number of international students studying in US universities has been increasing for nearly a decade (Redden, 2014). During 2013-14, there were nearly 886,052 international students in the US. Compared to 2012-13, there was an $8.1 \%$ increase in 2013-14; much of the increase was driven by students coming in from China which was up $16.5 \%$ and Saudi Arabia which was up 
$21 \%$. To put things in perspective, since the year 2000, there has been a $72 \%$ increase in international student enrollment in the US.

Enrollment of international graduate students also continues to increase. The Council of Graduate Schools reported a 10\% increase in the number of applications from international graduate students from 2013 to 2014 (Redden, 2015). During 2013-14, applications from graduate students from India and China represented $67 \%$ of all international applications received (Redden, 2015). Geographically, all four major regions in the US (West, Midwest, Northeast, and South) saw an increase in the enrollment of first-time international graduate students (Kent, 2013). With respect to field of study, while physical and earth sciences together accounted for $47 \%$ of all international graduate student enrollment in 2013, there was an increase in several other fields including Arts \& Humanities, Business, Education, and Social Sciences (Kent, 2013).

The rationales for recruitment of international students in US campuses are plenty, a primary reason being economic. As the Midwest and Northeast regions of the US continue to experience a decline in the number of high school seniors (Martin, 2013), international student enrollments are an essential source of revenue for post-secondary institutions (Andrade, 2006). International students also contribute to intercultural education and a greater understanding of diversity and global issues in the classroom (National Association for Foreign Student Advisors [NAFSA], 2003). In addition, universities with a large global presence often have several cultural events where international students share their food, traditions, dressing norms, and music with their US counterparts. Although there are numerous benefits to having students from other countries in US classrooms, institutions should recognize academic difficulties and offer appropriate programming.

\section{English-language Challenges Faced by International Students}

Spurling (2007) stated that universities tend to see international graduate students as "subject learners" and ignore the fact that they are also "culture and language learners" (p.114). Graduate students from specific countries have reported feeling apprehensive about speaking with native English speakers due to language deficiencies (Ranta \& Meckelborg, 2013). Choi (2006) concluded after interviews with 14 Asian graduate students enrolled in an American university that participants struggled with writing, speaking, and listening. This led to unfair perceptions or underestimation of their true academic abilities (Choi, 2006). Hanassab (2006) stated that a sense of isolation and lack of belonging was highest among Asian, Middle Eastern and African students (both graduate and undergraduate) compared to international students in western universities from other parts of the world. Liu (2011) added that East Asian graduate students faced more 
significant language barriers in English-speaking countries due to a larger gap between their native language and culture and English.

Existing tests and language support services available to international students seem to be inadequate. Although students must obtain minimum scores in English proficiency tests such as Test of English as a Foreign Language (TOEFL) and International English Language Testing System (IELTS), these tests do not always reflect actual proficiency needed to matriculate to succeed in graduate-level subject coursework (Schmidt \& Gannaway, 2007). There is also further need for language training despite meeting minimum scores in English proficiency tests because students are asked to debate ideas and critique viewpoints and they do not feel prepared to do so (Schmidt \& Gannaway, 2007). Language fluency, accuracy problems, and issues with grammar and vocabulary also continue after a semester of study in English-as-a-Second-Language (ESL) classes. Kim (2006) found that matriculated ESL students struggle with formal/academic language communications when they enter content classrooms. In one of a handful of studies focusing on English-language writing skills, Storch (2009) employed a test-re-test design to measure changes in academic writing after one semester of ESL classes. While the learners' writing did improve in terms of structure and content development, there was no improvement in fluency, grammatical accuracy, and use of academic vocabulary (Storch, 2009). Plagiarism also continued to be a problem. Storch (2009) also found out that instructors did not correct incorrect citations. In addition, instructors did not seem concerned about errors in writing of non-native speakers (Storch, 2009).

\section{Suggested Support Services to Improve English-language Communication Including Writing}

It is not enough to simply admit international students and expect them to automatically adjust to a new culture and educational system without relevant programming and support (Andrade, 2006). "If we want to attract and retain international students to our university campuses, we must focus on the students' needs and successes in the American university experience" (Lacina, 2002, p. 26). Support services that can be offered by universities to alleviate transitional challenges faced by international students do not necessarily need to involve new budgets or programs, but rather can be a result of redesigning existing programs and offering additional training to support services personnel (Andrade, 2006)

Sloan and Porter (2009) stated that it might be beneficial to place English for Academic Purposes (EAP) tutors within specific program areas to provide discipline-specific writing support. This type of physical placement within the academic unit would also allow for support sessions on the student's timetable. On a similar note, Andrade (2006) suggested 
offering content-based ESL courses. Ng (2008) also recommended that ESL staff collaborate with academic staff to develop tailor-made courses for students in specific disciplines.

Storch (2009) stated that the single most effective element for improvement of writing skills was to provide feedback on writing. The author suggested affording students the opportunity to submit a draft-inprogress so feedback can be provided before the final draft is submitted. Social immersion at home, university, work and community has been suggested to overcome English-language challenges. Rochecouste, Oliver, Mulligan, and Davies (2011) recommended that students join social groups; the authors suggested that names of such organizations and relevant events for students to participate in be included in syllabi. Liu (2011) recommended that foreign students live with native-English families or other international students who speak other languages and come from other cultural backgrounds. Interaction with host nationals has been linked to a feeling of ease and comfort resulting in being better able to express oneself (Moores \& Popadiuk, 2011). Although universities do engage in offering social adjustment programs, Rose-Redwood and Rose-Redwood (2013) stated that such programs could be more effective if they abandoned the assimilist doctrine of adjustments and instead promoted mutual engagement not just between foreign nationals and host nationals but also amongst the diverse foreign nationals. There may however, be challenges associated with attempts made at social immersion. For example, upon surveying Chinese students, Longerbeam et al. (2013) found that Chinese students perceived that US students were not interested in them when they sought friendships with US peers.

Group work also had an impact on improving English communicative competence. For example, Xue (2013) concluded based on interviews with 14 Chinese graduate students that group work improved participants' grammatical competence, sociolinguistic and strategic competence in English. Other suggestions that have been made to improve English-language communication skills or specifically writing include: (a) using technology tools such as electronic dictionaries or recommending specific websites such as www.grammar.com (Kasapoglu-Akyol, 2010); providing additional time for completing academic tasks (Khawaja \& Stallman, 2011); offering a pre-departure course focused on reading and writing (Yates \& Trang, 2012); peer mentoring and role model programs for newcomers (Huang, 2012); and offering online classes as this delivery mode may allow for improvement of writing skills as it allows the opportunity to edit and revise before posting online (Tan, Nabb, Aagard, \& Kim, 2010).

Little research has been published on language-learning experiences of international graduate students (Liu, 2011) despite advantages such as increased confidence and improved academic achievement (Andrade, 2006). 
After reviewing 58 journal articles on international graduate student development, learning, and experiences including those related to Englishlanguage learning, Renn, Brazelton, and Holmes (2014) stated that little new knowledge has emerged about students' adjustment to the host country. Arkoudis and Tran (2010) stated that views of students and lecturers regarding strategies they use to develop academic writing within the discipline is lacking in existing literature. Much of the existing research focuses on supporting ESL students. However, typically, universities position ESL as a service area that is separate from the core business of disciplinary teaching and learning (Arkoudis \& Tran, 2010).

Given the gap in literature with respect to English-language writing challenges faced by international graduate students while the number of these students continues to grow, the following research questions are explored in this study:

1. What English-language writing challenges are faced by international graduate students in the US, whose first language is not English?

2. What strategies could be utilized by instructors and at the department and institution levels to improve English-language writing skills for international graduate students in the US, whose first language is not English?

\section{METHOD}

This is a qualitative study (Merriam, 2009: Patton, 2002) seeking to better understand the writing challenges experienced by international graduate students and how those students believe the challenges faced can be addressed. The use of qualitative methods meant data were gathered in a natural setting (i.e., university); a human instrument was utilized for data collection (i.e., researcher); qualitative methods were used to collect data (i.e., in-depth interviews); and inductive data analysis was used (Lincoln \& Guba, 1985).

\section{Participant Recruitment and Administration}

Prior to participant recruitment, approval of the higher education institution's Institutional Review Board for research on human subjects was obtained. A list of international graduate students enrolled in a program of study was obtained from the office serving international students and scholars on campus. Individuals from the list were then contacted to participate in the study, with purposeful efforts made to obtain diversity with respect to field of study and countries represented. In order to participate in the study, students should have fulfilled the following criteria: (a) the medium of instruction should have been a language other than English during high school and undergraduate education; (b) the duration of 
stay in the US should be three years or less; (c) the degree pursued should be tied to a specific major (as opposed to students enrolled exclusively in ESL programs).

In-depth interviews are appropriate when the research is trying to gain a holistic understanding of a specific issue from the interviewee's point of view (Hesse-Biber and Leavy, 2011). Hence, this study utilized in-depth interviews as the goal was to explore English-language writing challenges faced by international graduate students and their perceptions of strategies that can be utilized to improve English-language writing skills. Sample interview questions include:

1. Please describe how you feel about the writing expectations in graduate school?

2. What challenges related to English-language writing did you experience?

3. Please describe your understanding of plagiarism?

4. Please discuss what you think about the feedback you receive from your instructors on writing assignments.

5. What support services do you think need to be implemented in the classroom by the instructor to improve your writing skills?

6. What services do you think specific offices within the university should provide to help international students whose first language is not English, improve their writing skills? Offices may include: Office of Global Education, ESL programs, Library, Academic Support Services, etc.

7. How would you feel about ESL-instructors being placed within each department to assist with improving subject-specific Englishlanguage writing skills?

Data were collected through 15 in-depth one-on-one interviews, which were conducted with international graduate students. Data collection ceased when the moderator started to hear the same responses (Silver, Stevens, Wrenn, \& Louden, 2012). The interviews were semi-structured in nature and an open conversational style (Clough \& Nutbrown, 2007) was adopted to enable exploration of reasons, feelings, opinions, and beliefs (Ritchie \& Lewis, 2003). Interviews lasted between 40 and 55 minutes. To ensure confidentiality, participants were advised not to disclose any identifying information during the interviews. Participants received a \$25 gift card to one of two retail establishments in appreciation for their time and effort.

\section{Participant Profile}

As recommended by Ritchie and Lewis (2003), important contextual information was collected from all participants at the beginning of the interview (see Table 1). The 15 participants represented 11 countries 
and 11 different fields of study. Participants' fields of study included Geography, Chemistry, Business Administration, Translational Studies, Early Childhood Education, Public Health, Physics, Higher Education Administration, Curriculum and Instruction, Psychology, and Clinical Mental Health Counseling. As it was a criterion to participate in the study, the medium of instruction was not English in high school or during undergraduate education for any of the participants. However, all participants had enrolled in English-language classes in their home country. Duration of study in the US ranged from seven months to three years and 10 out of the 15 participants were female. Three of the 15 participants had enrolled in ESL classes for one to four semesters in the US. Seven participants held part-time employment either as a graduate assistant or intern working 20 hours a week. Ten participants reported that they belonged to a student organization.

\section{Data Analysis}

All interviews were audio-recorded upon obtaining the participant's permission (Hesse-Biber \& Leavy, 2011). At the conclusion of all the interviews, the recorded audio data was transcribed, coded, and analyzed for emerging themes (Rugg \& Donne, 2011). As recommended by Song and Cheung (2010), to ensure credibility of the study, an independent researcher who was not involved with the study design and did not participate in the data collection was recruited to determine themes after reviewing the transcripts, abstracting data, and developing matrices to organize themes generated from the in-depth interview questions (Fulkerson et al., 2011).

Table 1. Demographic Characteristics of Respondents $(\mathbf{N}=15)$

\begin{tabular}{ll}
\hline Demographic Variables & Proportion \\
\hline Average duration of stay in the US & 2 years \\
Average duration of study in the US & 1 year 8 months
\end{tabular}

Gender

Male

$33.33 \%$

Female $66.66 \%$

Participants who took English courses while pursuing $80 \%$ undergraduate degree in home country Participants who took English tutoring classes while pursuing $\quad 40 \%$ undergraduate degree in home country

Participants who have taken ESL courses $20 \%$

Participants who currently have a part-time job $46.67 \%$

Participants involved in a student organization $66.67 \%$

Participants involved in volunteer activities in the community $\quad 20 \%$ currently or before 


\section{RESULTS}

The participants overwhelmingly agreed that they faced significant writing challenges with respect to writing semantics, presenting ideas in a logical manner, and plagiarism, regardless of their field of study. All the participants agreed that the expectations for writing in the U.S. were very high and that they desired assistance from instructors, peers, friends, technology tools, and various university resources catering to the unique writing needs of international graduate students. Below is an elaboration of various themes generated.

\section{Writing Challenges}

Academic writing posed a specific challenge for students whose first language was not English. For the participants in this study, writing in English at a graduate level created a new set of challenges not only because their previous studies had been in their mother tongue, but also because the standards at American universities regarding writing quality, vocabulary, and academic honesty were much higher than what they were used to at their former universities in their home countries. All of the participants commented that the writing expectations were very high leading to feelings of uncertainty in improving their academic performance. Key challenges faced by international students with respect to writing in English concerned grammar and vocabulary, style guide use, organization and flow of information, critical thinking, understanding of plagiarism, and assignment completion time; some of these challenges surfaced due to the differences in these areas compared to the expectations in their home countries. As expressed by one student, "It's just like, you see how people swim but you are not in that pool and you can't swim."

Grammar, vocabulary, and style guide. Learning grammar by rote in previously attended institutions caused difficulties in transferring the knowledge into academic writing. One of the participants shared, "I know lots of the rules of the grammar, but how we learn though, we just memorize them from the textbook, fill in the blanks, then when we speak, we even didn't know we speak right or wrong, nobody actually corrected us." Another student articulated a sense of disappointment in his grammar and writing ability, "my sentences are not right grammatically...I cannot put kind of my thoughts together and then when it comes to the graduate level." Insecurity in knowing if they were using the correct grammar was also reflected in the participants' dialogue on the use of specific vocabulary. One participant expressed concern, "What worries me most is to use the right words. Like the right vocabulary for a situation." Participants consistently stated that each field of study or program has its own lexicon. 
One participant expressed, "there's specific terminology for that, you have to use it; you cannot just say the light just goes, no, it propagates."

The participants all voiced concern that their spoken English was better or at least better understood than their written English, causing a feeling of diffidence. One participant articulated, "I don't feel much a problem communicating orally. But, as for writing, I feel like 'cause, there's this certain vocabulary expected on a written form so that...I was concerned...'cause I felt like I didn't know that."

Creating citations utilizing APA or MLA was new to many of the participants. One participant said, "I didn't know anything about APA before I came here.” In previously attended universities students were not often expected to use a specific citation style; therefore, upon pursuing graduate studies in the U.S., the students had to learn to use the official citation styles as required by their professors and programs. This participant iterates learning challenges related to using APA for the first time upon entering graduate school, “at first, I don't know what's APA, but when my professor first talk about it he provide a website to helpful for our international student to do the research. I checked the website but, still I'm not very clear. Then I got the textbook for APA and that helped but I need to follow the guides [every time I write]."

Organization and flow of ideas. Because writing in English is structured differently than other languages, organizing graduate level papers posed a variety of challenges. One participant discussed the difficulties she faced, "writing a paragraph, the topic sentence thing that in France, the topic sentence is actually at the end of the paragraph, so you have to reorganize the paragraph so it makes- it's different, the organization of a simple paragraph is different in France." She expands by stating, "during that first semester it was mostly organizing ideas because I was used to writing the way we do in France, so these first papers I had to go back and make sure all my topic sentences were there and I had examples and that I was quoting people properly, all of that- that is what the feedback was mostly about. The organizing my ideas.” In expressing disappointment in the organization and flow of international students' writing, one participant stated, "when I read even English writing, sometimes you can tell like, who's international writer and who's native speaker writer because the flow of the paper, the writing style would be a little bit different. So that's what I feel like I need to improve more."

Critical thinking. Critical thinking is a key component of American university education and it is expected that all students can engage deeply in the process through reading, reflection, synthesis, analysis, and writing upon entrance to graduate programs (Paul, 2005). Many international students have little exposure to the process before coming to the U.S. (Kettle \& Luke, 2013). With memorization and rote learning being 
the most common method of teaching and learning amongst the interview participants in their home countries, critical thinking and a lack of understanding of how to express original ideas were particularly challenging. One participant described the writing expectations in a previous non-American university, "at the school, when we do writing for instance, you read a text and then you write what you-, it's not what you think about the text, but what you remember actually so sometimes they called it essays...So it's more the facts." Another student stated, "They think you reflect, you synthesize, you analyze, and these are completely new skills that we never even heard of back home. My very first assignment [here was] when my professor [said he] want me [to] please reflect on it I, and I of course would not tell in front of everybody I don't know... what do you want from me?" When asked what the most challenging aspect to writing at a graduate level in an American university was, one student stated, "it would be the thinking, critical thinking, like how to make a paper sound and meaningful."

Plagiarism. When asked about plagiarism the majority of the participants claimed to know what it was and iterated they had attended workshops on plagiarism at the orientation sessions held at the beginning of the semester. However, even with the multitude of discussions on plagiarism at the university, most of the participants did not have a clear understanding of the ramifications of plagiarism, although they did state they knew it was a serious issue and should be avoided. One participant explained, "My understanding is that plagiarism in [the] United States is a very serious problem and you know most people take it very seriously. In my home country, the citation is not really important and [the] professor[s] often focus on the content of the paper." The importance of not committing plagiarism was expressed by another participant, "We hear more about it...for every class we hear about it. I feel like in France I only heard about it for the big project and not for everyday paper, but here it's in the syllabus and the emphasis is on it so you can't say you didn't know because you've been told what it is and why you shouldn't do it."

Assignment completion time. Although each international student participant stated that it took significantly longer than their American peers to complete the same writing tasks they did not wish to have additional time to complete their out of class assignments. "I was working very hard sometime I need 14 hours a day to raise my ability to write," stated one participant. Participants confirmed that the more they practiced writing the better they got at it; however, they suggested that if a writing assignment was given in class, that international students should be given extra time for completion. As one participant stated, "But there's one thing about in classroom writing, like faculty just give us a paper and asks us to write our ideas...I need more minutes.” 


\section{Strategies to Alleviate Challenges}

During the interviews the participants gave freely (or were asked to share specific) suggestions on how to improve their academic experiences at American universities, particularly in writing. Students expressed a need for additional feedback on writing from faculty, friends, peer mentors, and the writing center. They also discussed the role of ESL services, technology tools, and university orientation programs in improving writing skills. Lastly, participants discussed the relationship between use of verbal English in social situations and its connection with improved writing skills.

Feedback from faculty. A majority of the participants expressed disappointment that they did not receive helpful feedback from their professors. One participant summarized his experience: "I never actually got that specific feedback. Even like, 'please recheck this sentence grammatically or please rethink this point one more time'...it was just overall feedback. Sometimes it wasn't [feedback] at all...it was just the mark or the point off. Sometimes it was in a hand written that I even didn't understand...I don't know where is the problem. So if I would know 'in this sentence, please revise the grammar, or in this sentence, please, think more critically about that or think in a different way'."

Several participants felt that American professors were too gentle when they provided feedback. As one participant stated, "I think maybe they don't want to offend you or somehow. And I always get "A" but I know it's not the case. Then at one point, I'll say well, there is something wrong with the system. Why are they giving you "A" all the time? You know, I don't know.” Non-native American professors were seen as more helpful to international students with respect to improving writing quality. One participant stated, "my other professor, not from U.S. give[s] me more feedback on my writing itself...how that idea flow and is important, but also how I write.” Another stated, "I experienced 2 different professors. One was, American, native speaker, so every time I send him some of my writings, he would just, correct some of my mistakes but focused on the research idea. And my other professor was not from here. He was also an international one, so every time I send my writing to him, he would just do half and half...half of his comments were about my idea, research project itself, and half of the comments or feedback would be my, on my writing. So I thought maybe second language speaker, would pay more attention to another second language speaker's writing."

Expressing a difference in university culture between American and non-American schools one participant stated, "They [professors] are expecting us to go there in their office. That's something that's different from my country. Like, we don't have office hours and we don't really see our professors in their offices. Here, they expect you more to go to them I guess. They don't really give you return feedback, they want you to go ask I 
guess.” Several participants discussed feeling shy and timid to approach professors. A related unease felt by international graduate students was with respect to taking too much time out of their professors' schedules to ask for assistance, such as this student's concern, "in my opinion, I think first, I don't want to bother my professor[s] a lot." Participants who did take advantage of one-on-one meetings with professors outside of the classroom found them to be very beneficial; one participant stated, "Because whole class situations can be intimidating to international students who are insecure about their abilities working on individual projects one on one with professors came up as a way to improve writing skills and build confidence.”

Participants gave several helpful suggestions that professors can adopt. Students suggested that printed handouts would help them to better digest material discussed orally in class. As one participant shared, "it's very hard to work on that skill during the class. But I really love when people come with these printed form of the lecture or the instruction so I can see it.” Using a recording device was also noted as a beneficial way to review class lectures to more thoroughly understand complex discussions and topics. "I can tell you that in the first semester, I didn't understand anything of some classes. I just used to record classes and then transcribe, but in the second semester it was much better. There are still some difficulties in classes when the professor talks very fast, but I'm much better than before now," stated one student.

Feedback from friends. While some participants felt comfortable asking friends to give feedback on written work others did not want to burden their friends with the task of reviewing and editing their work. One participant claimed, "I also wouldn't like to be a burden for people who are usually very busy as well."

Participants who did ask for feedback on written assignments from friends thought it was beneficial as it was a good way to correct grammatical errors, and improve creativity and flow of the writing. One participant expressed, "some of the work...was a bigger assignment or a more important assignment I think one or two or three times I would ask someone to read it over just to check of my grammar and punctuation is ok. Not so much the style or the language, just the minor errors, but that are so essential to good writing." Another participant expressed, "Sometimes when it's a creative task, I'm thinking well, I could also make the text that...more creative...I could include a nice idiom, which I currently don't know, but a native speaker would come up with something more creative right away because he has the idioms stored in [his] head...those are instances where I definitely would ask someone for help.”

Assistance from peer mentors. Participants unanimously desired establishment of a peer mentor program; as one participant stated, "I would 
say that [having a peer mentor] could be useful, certainly. I have no formal kind of support, some very, kind graduate students who were either second or third year, not necessarily of my language patterns, Spanish speaking, but they were quite useful explain[ing] how things work in the department, what I could expect from professors, what faculty expected from me.”

Participants overwhelmingly preferred having a peer mentor from the same graduate program as opposed to having peer mentors from their home countries. Although it was acknowledged that peer mentors from the same country could help new international students navigate cultural barriers and everyday life, mentors from the same department would have specific technical knowledge and related vocabulary and would be able to help new international students understand departmental procedures such as course selection and registration. As one participant stated, "I think it would have been most beneficial if that person would have also been in the same master's program that's probably the most crucial thing." Another participant concurred, "I think it may be more helpful if he or she [is] [peer mentor] from my own program [because they know] how to do the assignment and the paper in the right way...the senior student, they would know how much time I need for my research or my assignment.”

Feedback from the campus writing center. The participants of this study felt the writing center on campus was not very useful in meeting their needs as graduate students. As one participant voiced, "There is a writing center [and] there are volunteers, they have to be American, native speakers. So they volunteer to work there to help international students to look at our writings, and correct our writings. So we go there like, one hour- it depends on how long your writing is. [However the] maximum they give you [is] one hour every day. So if you have a term paper, [and] you had 20 pages you might need to go there several times, because they only work for one person for one hour." Another student added, "As a graduate student, I felt like sometimes um, the writing commons would focus on your language use, but they don't necessarily know the academic content." "I always go to the Writing Common, they would actually do my spell check or my grammar or it was very minor, however, the academic content of the paper was not addressed,” expressed a participant.

University ESL vs. Department-specific ESL services. Most of the participants felt the current model of ESL assistance was lacking in ways that would be beneficial to graduate students seeking to improve disciplinespecific academic writing. Participants suggested employing departmentspecific trained ESL personnel to assist with graduate-level academic writing. "If it's specific about writings in our field I prefer that someone who has knowledge about my field, like I'm from marketing, so I hope this person knows a little bit about marketing. It's just like when you submit something, the editors may just look at your writing, but if you have 
someone who knows your field, [they] would give you better advice. I think it depends on what you seek. If you want just general writing advice, for me it doesn't matter whether ESL has an office in our building, but if this person knows both, knowledge plus writing skills, that would be helpful," stated one participant echoing the sentiment of several others.

Technology tools. All the participants in this study used technology to boost English language skills while specifically seeking to improve technical writing. International students watched news programs, YouTube videos, and TedTalks. As one participant put it, "sometimes I listen for the CNN News to...improve my ear of listening to English, 9 - 10 hours a day." Another preferred reading to watching, "I just read uh CNN and NPR website.” TedTalks, Facebook, and Twitter helped to improve English vocabulary; as one of the students explained, "Sometimes I stop the [TedTalk] players and see the structure...then I translate it to my paper. Sometimes I subscribe with the Twitter or also the Facebook with something that relates to major.

To improve their writing skills, the participants used a variety of websites such as Google Scholar, dictionary.com, Live Mocha, Grammar Monster, Lingoes, Grammar Pages, Purdue OWL, Son of Citation among others. One of the students explained, "Lingoes. It's also a website...but it's more like an app that you can download on your phone. It's also a translator. I think it does a good job when I compare like, different translators 'cause it's more like a platform that you can input like, different dictionaries in it so, you can get a meaning from all the different dictionaries so you can compare instead of just get one source." To be sure they are following specific steps in the writing process one participant reflected, "YouTube will have some video about like how to make your reference list...step-by-step."

Many participants used technology to be certain they were producing original work; "there are some websites that tells you if your writing is not copying other people's [work]," stated one participant. Another participant used web technology she was more familiar with; she expressed "There's a Chinese website, they have the lecture from the University. It's online, we can watch that for free...specific for the writing. It's called Wangyi."

Orientation programs - graduate vs. international. The participants overwhelmingly agreed that the international student orientation program was geared towards undergraduate students. The graduate student orientation, while helpful in some areas, lacked specific sessions for international graduate students; as one participant described, "It seems a little bit disconnection (sic) because graduate student orientation is for graduate students but there's nothing particular for international graduate students. And then the international student orientation is kind of more focused on undergrads.” 
With respect to the international student orientation, participants commented that there was a lot of discussion about immigration, but not enough information on how to succeed academically in U.S. One participant described, "They mostly talk about immigration, visa, how to not be illegal here, what not to do, just the University in general. I don't think they talk specifics about the expectations of writing and things. Maybe they could introduce that for like, small groups. Maybe people can talk about their experiences and then they can explain how it can be here.” Another student agreed, "The international student orientation is kind of more focused on undergrads." Another participant stated, "Have a separate workshop for international graduate students.”

Participants felt that the graduate student orientation offered sessions on professional development, such as attending and presenting at conferences, publishing research, and teaching in the university for current and future teaching assistants. A participant who was not hired to be a graduate assistant expressed disappointment with the graduate student orientation, "they could talk more general about the grad students. They focused more on teaching I guess like, some of grad students are gonna be teachers so they focus on situations that they're gonna face if you're a teacher I guess so it was kind of not related to people that are not going to teach. And they spent a lot of time on those kind of situations and what to do with the students and like, if there's a student with depression or if there is disability or something like that. So maybe they could just talk more generally about the resources we have, where to find things, what's going on in the University for grad students, events, things like that.”

Another student suggested, "probably if we had an opportunity to meet other students in our department, or our cohort that would be better because I didn't feel really good in GSO (graduate student orientation), because I didn't know anybody, I was new to everyone everywhere. I didn't know anywhere." Participants did express that they found the session on plagiarism to be very useful.

Social use of English. Students who used English often in social situations tended to gain better spoken English language skills leading to more confidence living in the US, which, according to the participants, lead to an improvement in their academic skills. As one participant stated, "I have a boyfriend who is not Chinese, so I have to speak English every day." "I think it helped a lot being in this environment, immersing in the culture" explained another participant. Working outside the home and in addition to their studies also led to a heightened sense of cultural awareness and improved language skills, as this student explained, "I think it helped a lot being in this environment, immersing in the culture...because I am working in my lab, I have to deal with native speakers all the time.” 
Several students participated in the conversational partners program organized by the office that served international students and scholars on campus. Their goal was to practice English in social situations. Participants in the program felt it did not help them gain better spoken language skills, either because the American student they were paired with lacked robust conversation skills or there was not sufficient time to spend with their conversation partner. As one participant described, "she [American student] wasn't very talkative. I think in this program, somebody talkative should be in charge of these things. She was just listening and she didn't give us that much feedback." Another student noted, "I just went to international office and requested for a conversation group. An American girl came with us in a few places on campus, for I think two or three sessions - we just talked for an hour and it was not bad. But she did not contact us anymore.”

\section{DISCUSSION AND IMPLICATIONS}

This study investigated one area of concern amongst international graduate students related to English-language writing challenges and found there is room for improvement with respect to services provided by HEIs to help alleviate these challenges. Participants indicated they experienced a variety of writing challenges during their graduate education and they made a few suggestions for helping to alleviate those challenges. It is important to note that these graduate students met or exceeded the minimum scores on the standardized English language proficiency exams (e.g., TOEFL).

The participants in this study were all graduate students who met the criteria for admission. One might expect the English proficiency of these students' to be at a level sufficient enough to write papers at the graduate level. However, even though they performed well enough on the standardized exams, academic writing still posed a difficulty. Participants believed they had deficiencies in grammar and vocabulary, organization and flow of information, critical thinking, plagiarism, and the use of writing style guides.

Participants in this study confirmed the need for on-going English language skill development throughout a student's program. They indicated a need for faculty members to provide more detailed constructive feedback on writing assignments. These students expressed the need for feedback on content and writing, as opposed to just content. Graduate school is still a time for learning and international graduate students need to learn to be effective writers as well as content experts. Students expressed a desire to meet with faculty members regularly outside of the classroom environment. These meetings, whether individually or in small groups could provide an excellent opportunity for faculty to provide feedback on writing concerns. 
Several of the participants believed that support for their writing should begin at orientation. They commented on the structure of the international student orientation indicating a need for discussion of more than immigration rules. They suggested the institution spend more time on the academic transition and the importance of writing at the graduate level. Few of the participants were exposed to the style guides used in the U.S. so introducing these during orientation can help international students prepare for some of the graduate-level writing expectations that lie ahead. This could also be accomplished through a pre-departure program similar to the one recommended by Yates and Trang (2012).

The participants specifically requested an orientation program that focused on the needs of international graduate students. The current structure at the HEI where the participants were enrolled in this study had two orientation programs; one focused on international students, which was viewed as being more appropriate for undergraduate students, and the other was a graduate student orientation program that included both domestic and international students. The orientation program could also focus on stressing the importance of international students using English, as often as possible, in social situations. Several participants felt that this improved their vocabulary and hence their academic writing skills.

Another support structure that international graduate students value is that of peer mentoring. Similar to the findings of Sloan and Porter (2009) there was a great deal of support for having peer mentors, who were preferably in the same discipline, to assist with writing concerns as they would be familiar with discipline-related terminology. The hope is that individual faculty members or the academic department would provide such a program or at the very least endorse a peer-mentoring program that is offered through another unit on campus. Peer feedback was viewed as an important aspect of a student's graduate experience, which reinforces the findings of the Storch (2009) study.

Many HEIs with international graduate students also have ESL programs with expertise on preparing those students for academic success on their respective campuses. There is an opportunity here for ESL faculty to partner with writing center staff to help differentiate the needs of English language learners and native speakers. Several participants in this study noted the limited experience of the writing center staff and also their limited understanding of international graduate student needs. Participants strongly endorsed the idea of employing department-specific trained ESL personnel so they can get assistance with writing quality within a specific field of study.

Finally, participants mentioned their use of technology in language skill development. Technology was seen as a tool to assist not a solution. Perhaps there is a way for faculty to incorporate more of these technology 
tools into their courses to supplement other language skill development techniques being used. More research needs to be conducted on the uses of today's technology tools.

Being a qualitative study conducted at a single institution, the results and findings presented are not meant to be generalizable but rather used as a bridge to further research. As U.S. institutions of higher education become more dependent upon international students, researchers need to continue the exploration of international graduate student needs. Researchers are encouraged to add to the body of literature on international graduate students in hopes of being able to find generalizable alternatives to meeting the needs of this population. Previous researchers have explored social adjustment and legal issues; however, there seems to be a gap in the literature with regard to the academic transition of international students, especially at the graduate level.

\section{REFERENCES}

Andrade, M.S. (2006). International students in English-speaking universities. Journal of Research in International Education, 5(2), 131-154. doi: $10.1177 / 1475240906065589$

Kasapoglu-Akyol, P. (2010). Using educational technology tools to improve language and communication skills of ESL students. Novitas-ROYAL (Research on Youth and Language), 4(2), 225-241.

Arkoudis, S., \& Tran, L. (2010). Writing Blah, blah, blah: Lecturers' approaches and challenges in supporting international students. International Journal of Teaching and Learning in Higher Education, 22(2), 169-178.

Choi, T. (2006). Asian international students' academic adjustment in a U.S. graduate school and Stanton-Salazar's framework. Pacific Asian Education, 18(2), 51-68.

Clough, P., \& Nutbrown, C. A student's guide to methodology ( $2^{\text {nd }}$ ed.). Thousand Oaks, CA: Sage Publications, Inc.

Desilver, D. (2013, November 12). Record number of international students studying in the U.S. Retrieved from http://www.pewresearch.org/fact$\operatorname{tank} / 2013 / 11 / 12 /$

Ferris, D. (1998). Students' views of academic aural/oral skills: A comparative needs analysis. TESOL Quarterly, 32(2), 289-318. Doi: $10.2307 / 3587585$

Fulkerson, J. A., Kubik, M. Y., Rydell, S., Boutelle, K. N., Garwick, A., Story, M., Neumark-Sztainer, D., \& Dudovitz, B. (2011). Focus groups with working parents of school-aged children: What's needed to improve family meals? Journal of Nutrition Education and Behavior, 43(3), 189-193. Doi:10.1016/j.jneb.2010.03.006

Hanassab, S. (2006).Diversity, international students, and perceived discrimination: Implications for educators and counselors. Journal of Studies in International Education, 22(1), 7-16. Doi: 10.1177/1028315305283051 Hesse-Biber, S.N., \& Leavy, P. (2011). The practice of qualitative research $\left(2^{\text {nd }}\right.$ 
ed.). Thousand Oaks, CA: Sage Publications, Inc.

Huang, Y. (2012). Transitioning challenges faced by Chinese graduate students. Adult Learning, 23(3), 138-147. Doi: 10.1177/1045159512452861

Kettle, M., \& Luke, A. (2013). The critical meets the cultural: International students' responses to critical, dialogic postgraduate education in a western university. In Sovic, S. \& Blythman, M. (Eds.), International Students Negotiating Higher Education: Critical perspectives (pp. 104-123). London: Routledge.

Kent, J. (2011, November 5). First-time enrollment of international graduate students up 10\%. Council of Graduate Schools. Retrieved from http://www.cgsnet.org/sites/default/files/Intl_III_2013_release_final_0.pdf

Khawaja, N.G., \& Stallman, H.M. (2011). Understanding the coping strategies of international students: A qualitative approach. Australian Journal of Guidance and Counselling, 21(2), 203-224. Doi: 10.1375/ajgc.21.2.203

Kim, S. (2006). Academic oral communication needs of East Asian international Graduate students in non-science and non-engineering fields. English for Specific Purposes, 25(4), 479-489. Doi:10.1016/j.esp.2005.10.001

Lacina, J.G. (2002). Preparing international students for a successful social experience in higher education. New Directions for Higher Education, 117, 2128. Doi: $10.1002 /$ he.43

Liu, L. (2011). An international graduate student's ESL learning experience be yond the classroom. TESL Canada Journal, 29(1), 77-92.

Longerbeam, S.D., DeStefano, T.J., \& Lixin, Y. (2013). "We cannot reach them": Chinese undergraduate student perceptions of the U.S. campus climate. Journal of Student Affairs Research and Practice, 50(3), 326-344. Doi: 10.1515/jsarp-2013-0023

Martin, A. (2013, January 10). Downturn still squeezes colleges and universities. The New York Times. Retrieved from http://www.nytimes.com/2013/01/11/

Merriam, S. B. (2009). Qualitative research: A guide to design and implementation. San Francisco, CA: Jossey-Bass.

Moores, L., \& Popadiuk, N. (2011). Positive aspects of international student transitions: A qualitative inquiry. Journal of College Student Development, 52(3), 291-306. Doi: 10.1353/csd.2011.0040

National Association for Foreign Student Advisors [NAFSA]: Association of International Educators. (2003). In America's interest: Welcoming international students. Retrieved from https://www.nafsa.org/

Ng, B. F.Y. (2008). Studying abroad: Learning (in) English. The International Journal of Learning, 15(9), 237-246.

Paul, R. (2005). The state of critical thinking today. New Directions for Community Colleges, 2005(130), 27 - 38.

Poyrazli, S., Arbona, C., Bullington, R., \& Pisecco, S. (2001). Adjustment issues of Turkish college students studying in the United States. College Student Journal, 35(1), 52-62.

Ranta, L., \& Meckelborg, A. (2013). How much exposure to English do international graduate students really get? Measuring language use in a naturalistic setting. The Canadian Modern Language Review, 69(1), 1-33. Doi: $10.3138 / \mathrm{cmlr} .987$ 
Redden, E. (2014, November 17). International enrollment up. Inside Higher Ed. Retrieved from https:/www.insidehighered.com/news/

Redden, E. (2015, June 30). International grad student apps increase. Inside HigherEd. Retrieved from https://www.insidehighered.com/news/

Renn, K. A., Brazelton, G. B., Holmes, J. M. (2014). At the margins of internationalization: An analysis of journal articles on college student development, learning, and experiences, 1998-2011. Journal of College Student Development, 55(3), 278-294. Doi: 10.1353/csd.2014.0029

Ritchie, J., \& Lewis, J. (2003). Qualitative research practice: A guide for social science students and researchers. London: Sage Publications, Inc.

Rochecouste, J., Oliver, R., Mulligan, D., \& Davies, M. (2011). The English language growth project. Australian Universities Review, 53(1), 102-104.

Rose-Redwood, C.R., \& Rose-Redwood, R.S. (2013). Self-segregation or global mixing?: $\quad$ Social interactions and the international student experience. Journal of College Student Development, 54(4), 413-429. Doi: $10.1353 /$ csd.2013.0062

Rugg, N., \& Donne, V. (2011). Parent and teacher perceptions of transitioning students from a listening and spoken language school to a general education setting. The Volta Review, 111(3), 325-352.

Schmidt, L., \& Gannaway, D. (2007). E-Learning to aid international student transition. International Journal of Learning, 13(12), 55-60.

Silver, L., Stevens, R.E., Wrenn, B., \& Loudon, D.L. (2012). The essential of marketing research ( $3^{\text {rd }}$ ed.). New York, NY: Routledge.

Sloan, D., \& Porter, E. (2009). The management of English language support in postgraduate business education: The CEM model (contextualization, embedding and mapping). International Journal of Management Education, 7(2), 51-58. Doi: 10.3794/ijme.72.188

Song, H., \& Cheung, C. (2010). Satisfaction with loyalty towards theatrical performance in China: Evidence from a qualitative study. International Journal of Tourism Research, 12(6), 665-679. Doi: 10.1002/jtr.782

Spurling, N. (2007). Exploring adjustment: The social situation of Chinese students in UK higher education. Learning and Teaching in the Social Sciences, 3(2), 95-117. Doi: 10.1386/ltss.3.2.95_1

Storch, N. (2009). The impact of studying in a second language (L2) medium university on the development of L2 writing. Journal of Second Language Writing, 18, 103-118. Doi:10.1016/j.jslw.2009.02.003

Tan, F., Nabb, L., Aagard, S., \& Kim, K. (2010). International ESL graduate student perceptions of online learning in the context of second language acquisition and culturally responsive facilitation. Adult Learning, 21(12), 9-14. Doi: $\quad$ 10.1177/104515951002100102

Xue, M. (2013). Effects of group work on English communicative competence of Chinese international graduates in United States institutions of higher education. The Qualitative Report, 18, 1-19.

Yates, L., \& Trang, N.T.Q. (2012). Beyond a discourse of deficit: The meaning of silence in the international classroom. The International Education Journal: Comparative Perspectives, 11(1), 22-34.

Zhou, Y., Frey, C., \& Bang, H. (2011). Understanding of International Graduate 
Students' Academic Adaptation to a U.S. Graduate School. International Education, 41(1), 76-94.

SWATHI RAVICHANDRAN, MBA, $\mathrm{PhD}$ is an Associate Professor of Hospitality Management at Kent State University. Her research interests are primarily in hospitality human resources management and marketing. She also pursues research in international education. Email: sravicha@kent.edu

MARK KRETOVICS, MBA, PhD currently serves as an Associate Professor of Higher Education Administration at Kent State University and has been a Fulbright Specialist in Kyrgyzstan and Cambodia. His research interests include institutional politics, assessment of student learning, and business practices in higher education. Email: mkretov1@kent.edu

KARA KIRBY, MEd, PhD candidate in Cultural Foundations at Kent State University, is an IBPYP Curriculum Specialist and English teacher with the Global Ambassadors Language Academy. Her research addresses women's and girls' education and access to technology in Africa, international education, the capabilities approach, and qualitative methods. Email: kkirby4@kent.edu

ANKITA GHOSH, B.S. is pursuing her Master's degree in Hospitality and Tourism Management at Kent State University. Her research interests are in higher education, Hospitality human resources management, hotel operations, and revenue management. Email: aghosh8@kent.edu 